\title{
EVALUATING THE DEVELOPMENT OF SUSTAINABILITY COMPETENCIES AND KNOWLEDGE IN THE ARCHITECTURE AND DESIGN STUDENTS
}

\author{
Nuñez ME*, Rodriguez-Paz MX and Lozano RPM \\ Tecnologico de Monterrey, Mexico
}

\begin{abstract}
Innovation in learning and teaching in higher education permits greater impact on students in the context of the current form of communication. Compared to the traditional model of teaching. employing innovative teaching resources offers opportunities to explore different global perspectives and can help students recognize the complexities behind the world's current challenges, including that of Sustainable Development. This study is part of an investigation that, through different methods has collected information to address the need for innovative resources to promote Sustainable Development Education (SDE) more efficiently into the higher education curricula, specifically into the Architecture and Design programs. This study seeks to respond to the call for responsible actions, based on rational principles and ethical values to integrate Sustainable Development (SD) in the study plans through the design of a digital platform and an online test that allows architecture and industrial design students to evaluate the sustainability of their projects. A survey was applied for the first time in June 2020 to a sample of 145 students from nine Project courses; the main results of this first application are presented in this paper. An important finding so far is that it is necessary to integrate SD more firmly and more efficiently and that a deeper reflection in students about SD must be promoted. It is also important to provide the students with an adequate variety of resources for the development of their projects, such as: tests to evaluate sustainability, links to workshops, online games, complementary courses and conferences, videos and webinars with experts, among others.
\end{abstract}

Keywords: Sustainable development education, evaluation of competencies, higher education curricula

\section{Introduction}

This research is part of an investigation that, through different methods has collected information to address the need for online resources in Sustainable Development Education (SDE) for the higher education Architecture and Design curricula. In the previous stages, Sustainability experts were interviewed, a questionnaire was applied to 31 academics from 8 private and 6 public universities in Mexico, and interviews were conducted with students, professors and graduates from 4 campuses in the University.

The University where the authors are professors (Tecnológico de Monterrey, Mexico), has an annual call that promotes educational experimentation and innovation projects at a higher education level. The Project applied to this call in 2019 and was selected receiving a funding (150,000 Mexican pesos, 
equivalent to 6425 USD). This enabled the creation of an online platform for promoting and developing Sustainable Development (SD) Competencies in the students. This online platform seeks to enable SDE digital knowledge in the context of the current Educational Model TEC21 of the University, promoting active and collaborative learning in a real-world setting. (Tecnologico de Monterrey, 2018, p.12)

As part of this online platform, a test was designed to allow architecture and design students to evaluate the sustainability of their projects and to give them access to various digital resources on Sustainable Development (SD). In this way, the study seeks to respond to the call for responsible actions, based on rational principles and ethical values to integrate SD in the study plans. (Strang, 2010, pp. 132). The test was designed in a way in which after the students finish to answer it, the platform gives them feedback and recommended personalized digital resources according to their answers.

The survey was designed with the aims to: 1. Obtain data through surveys of a sample of students. 2 . Determine the topics, interest, content, and relevance of the SD material for the students. 3. Integrating suitable material to the TEC21 model and the development of competencies. 4. Identify the impact of the platform material on the project courses in control groups for feedback on its operation.

The results of the first survey application may affect the project by encouraging a deeper understanding on the application evaluation. Valuable feedback was obtained from the survey application that will help to improve the online platform. For example, the main topics that we need to reinforce through the online platform: $73 \%$ of the students do not know what a bioindicator is, 53\% have not considered the vulnerabilities of precipitation in their projects, 53\% have not considered the effect of climate change in your projects.

The results of the first application of the survey can affect the project by fostering a deeper understanding of the evaluation that is required in relation to the development of Sustainability competencies. Valuable feedback was obtained from the survey application that is helping us improve the online platform. For example, thanks to the survey we have identified the main topics that we must reinforce through the online platform: $73 \%$ of students do not know what a bioindicator is, 53\% have not considered the vulnerabilities of precipitation in their projects, 53\% have not considered the effect of climate change on their projects.

\section{Aim of the research}

The main objective of this paper is to present the results of the first application of the survey that was designed to evaluate the development of SD competencies and knowledge in the Architecture and Design students. This survey is part of an online platform launched in February 2020 with a focus on contributing to the creation of innovative approaches to the Design and Architecture curricula in ways that can constructively support ESD at Tecnologico de Monterrey (TEC) in Mexico. Another objective is to provide new insights into how the creation of innovative online resources and approaches can support ESD at TEC and SD in Mexico. 


\section{Context of the study}

Innovative methods of learning offer valuable and in the context of contemporary forms of communication, a more impactful experience, compared to traditional classes. Innovative courses can offer Design and Architecture students opportunities to explore different global perspectives and help them to learn about world issues and the complexities behind terms such as citizens of the world (Nuñez, et al. 2020, pp. 1-2). Due to the communications revolution, researchers are now aiming to take advantage of mobile technology for flexible materials for educational purposes. (Nuñez, M. E. and Rojas J.C., 2018, p. 5).

According to Marc Prensky (2014), an American writer and speaker on education, educators (digital immigrants) have to specialise in guiding the young, (digital natives) in the use of technology for effective learning, motivating them to learn through their own passion. He emphasises three aspects of the current educational discussion that have seldom been addressed together:

First, students in our classrooms are changing, largely as a result of their experiences with out-ofschool technology, and they are no longer satisfied with an education that is not immediately directed to the real world in which they live. Second, the pedagogy of 'counting and testing' that we have mostly been using in our schools has become less and less effective with students. We need a better pedagogy, and the good news is that it is available and can be used today. Third, that the digital technology that is now entering, more or less quickly in our classrooms, used correctly, can help to make our students' learning connected with reality, attractive and useful for their future. (Prensky, 2014)

In a complex socio-political-economic academic context, pedagogical innovation unquestionably prevails as one of the solutions to the challenges faced by today's university. It is a mediator for change and adaptation, marked more by human interaction than technique, supporting students and facilitating teaching and learning (Walder, 2016, p.1).

The call for innovation is ever present in the fields of science and economy. However, in Mexico, in Higher Education we still observe many traditional practices and not much progress has been made in the creation of more innovative approaches and spaces to encourage the creation of knowledge.

The creation of real learning environments able to deploy continuous processes of educational innovation requires education spaces with access to new information technologies and communication. Quality education requires a strengthening of infrastructure, basic services and equipping schools. (Gobierno de la Republica Mexicana, 2013).

This research recognises that definitions of innovation are constantly open to varying interpretations and revisions of those interpretations. However, in the context of this research, UNESCO's definition of 'innovation' provides a useful basis.

An innovation is the implementation of a new or significantly improved product (good or service), or process, a new marketing method, or a new organisational method in business practices, workplace organisation or external relations. (UNESCO, 2005) 
The following definition is also relevant to the social and economic contexts of the research as it includes social innovations.

The definition of innovation has broadened - it is no longer restricted to R\&D laboratories and to published scientific papers. Innovation also includes social innovations and business model innovations. (ECOSOC, 2013)

Godin (2015), an expert who collected over four hundred documents containing the word innovation in its titles, from the Reformation to the late nineteenth century, gives a representation of innovation from antiquity to the sixteenth century. According to Godin, the meaning of this word, in its origins was negative: For the ecclesiasts, innovation meant dangerous and to the political authorities, it meant conspiracy. In contrast, in the 20th century the concept of innovation has shifted to a concept concerned with economic benefits. Godin's definition of innovation is: 'Innovation is change to the established order, a change that is intentional, a change that brings radical or revolutionary transformations of society' (Godin, 2015, p.45).

Digital technologies have a key role in the creation of diverse social networks. According to Stebbing (2015), human creativity is the greatest resource that we possess, and he challenges us to use it for human and environmental welfare to create a sustainable future. He proposes communication and digital technologies for new sustainable and social infrastructures and to maximize cooperation to reconnect people and nature. (Stebbing, 2015, p.9)

Pedagogical innovation must result in transformation, a genuine change with positive effects. In this sense, an innovative learning environment is one that 'is capable of evolving and adapting as educational practices evolve and change - thus remaining future focused'. (Ministry of Education, 2014). As stated before, one of the questions this research aims to answer is: Why is creating innovative learning approaches of critical importance to SD in Mexico. For the purpose of this research the definition of innovation implies changes and transformations, but it can be applied gradually, step-by-step to generate a true positive change.

Guijarro (2016), states that Information and Communication Technologies (ICT) are essential to achieve the objectives of SD. He affirms that ICT are 'changing the world' and 'contributing to the development of societies at a level that can be considered as a basic need'. According to Guijarro, the text of the Sustainable Development Goals (SDGs) recognises the fundamental 'catalytic role' of ICT for development and states that 'the generalisation of information and communication technologies', as well as 'global interconnection, offer a great potential to accelerate human progress, reduce the digital divide and develop knowledge societies'. ICT are mentioned directly in four of the 17 objectives, as a driver of the new 'smart' infrastructures, and as essential instruments for implementing the SDGs.

Lahmidi et al (2019) have studied digital technologies and ESD. Through an analysis, they show the effectiveness of the use of digital technologies in ESD, their motivational and creative potential. They establish that digital technologies offer the possibility of creating 'new learning environments connecting formal education in the classroom with informal education'. They mention that the main pedagogical methodologies of ICT in favour of the ESD are: -Learning based on problems in real life. -Gamification. -Connect experiences and the exploration of real and virtual worlds. - Cooperative 
learning, (construction of the social network in learning communities). - Learning in communities (Wikis and Blogs). - Contextual learning, supported by digital inclusion and fostering intercultural understanding, social participation and social responsibility (Lahmidi et al, 2019, pp. 83).

The researcher's intention was from the origin to address the creation of innovative learning approaches as critical to SD in Mexico. One of the findings of Lahmidi et al (2019) is that all the documents that were found and analysed for their research are written in the language English, with few references in other languages, including the Spanish language (Lahmidi et al, 2019, pp. 83). An investigation into this provides new insights and adds to existing knowledge on the type of quality education that is required to support the Design and Architecture curricula, capable of addressing the challenges of sustainable economic and social progress in Mexico. (Nuñez, et al. 2019, p. 1).

\section{Method}

The criteria for the selection of the research methods for this inquiry are based on their ability to support the investigation of the broad and variable challenges of sustainability (Iniguez, 2016). According to Zidane, the use of different methods of data collection, 'allows the practice of triangulation to collect rich and varied information and to generate new ideas' (Zidane, 2015, p.57). Similarly, for Creswell, 'mixed methods permits collecting a variety of methods that neutralises the weaknesses of each form of data' (Creswell, 2014, p.43).

The University's Architecture (2011) and Design (2011 and 2017) curricula consist of ten and nine semesters respectively. Projects courses are taken in both careers continuously from the third to the last semester. A survey was applied in these courses, selected for their integrating purpose because in them the students apply in a practical way, the contents of the rest of their subjects. The survey was applied for the first time in June 2020 to a sample of 145 students from nine project courses.

The survey permits to evaluate the development of SD knowledge in the students as well as the development of five competencies established in the previous stages of the investigation (as presented in the Introduction section). The survey was designed by a team in which 3 teachers from 2 areas (Architecture, Design and Sustainability Sciences) and 3 students (Architecture, Digital Arts and Sustainability Engineering) participated. The survey was applied for the first time in June 2020, at the end of the Spring semester.

\section{Analysis and results}

The survey includes 29 questions grouped into 2 categories: ecosystem (integrating aspects related to the ecosphere, lithosphere, atmosphere and hydrosphere) and socio-economic (integrating factors of impact on health, economy and security). Three different group of questions were designed depending on the level of the students as shown in Table 1. Project courses 1 to 3 focus on collective housing, education and recreation while project courses 4 to 5 emphasize community buildings and mixed-use complexes. Projects 6 to 7 focus on advanced concepts of design, heritage value and sustainability. 
Table 1: Levels of the students for the survey application ( sample = 145 students)

\begin{tabular}{lll}
\hline Level 1 (40 students) & Project Courses 1 to 3 & Semesters 3 to 5 \\
\hline Level 2 (41 students) & Project Courses 4 to 5 & Semesters 6 to 7 \\
\hline Level 3 (64 students) & Project Courses 6 to 8 & Semesters 8 to 10 \\
\hline
\end{tabular}

Some results of this section include: $73 \%$ of the students in the Level 1 do not know what a bioindicator is, 53\% have not considered the vulnerabilities of precipitation in their projects and 53\% have not considered the effect of climate change in your projects. These are topics that will now be reinforced through the online platform.

Five questions measure the student's perception regarding the development of SD competencies:

1. Knowledge and understanding of SD problems at a local / global level.

2. Successful application of SD principles to projects and lifestyle.

3. Evaluation of the life cycle of the projects according to the criteria of minimization of the multiple environmental impacts.

4. Motivation to DS when presenting projects to the group.

5. Search for knowledge and experience from other disciplines to meet the sustainability requirements of the project.

Values range from 1 to 5 where 1 is low and 5 is high. In this section, the competencies 1, 2 and 5 had values of 3 or more for the three groups of students. For the students in the Level 1, low values for the competency number 3 (evaluation of the project's life cycle) stand out, since $75 \%$ of the students chose a value of 2; This is valuable feedback that will help to improve the online platform, it is a topic that is being reinforced through the digital resources that are offered there. For the students in the Levels 2 and 3 students, the opportunity area focuses on competence 4 (which implies that the student motivates their other classmates towards SD), $47 \%$ of the students in the Level 2 voted a value of 2 and $52 \%$ of the students in the Level 3 chose a value of 2 .

The next section in the survey included a question on the SD area in which the students would like to deepen according to their performance on the survey. The next table (Table 2) shows the results.

Table 2: Main SD Topics that the students selected to delve (sample = 145 students)

\begin{tabular}{lll}
\hline Percentage of students & Level of the students & Selected Topic \\
\hline $75 \%$ & Level 1 & Ecosphere \\
\hline $33 \%$ & Level 2 & Sustainability Wellbeing \\
\hline $21 \%$ & Level 2 & Atmosphere \\
\hline $24 \%$ & Level 3 & Sustainability Wellbeing \\
\hline $21 \%$ & Level 3 & Economics \\
\hline
\end{tabular}

Two questions evaluated the survey as a tool to promote SD: 1 . How necessary do you consider this survey as a tool to promote sustainability? 2. Did you find it intuitive and easy to explore? The next Tables (Table 3 and 4) shows the results. Values range from 1 to 5 where 1 is low and 5 is high. 
Table 3: How necessary do you consider this survey as a tool to promote sustainability? (sample = 145 students)

\begin{tabular}{lll}
\hline Percentage of students & Level of the students & Selected Value \\
\hline $75 \%$ & Level 1 & 5 \\
\hline $75 \%$ & Level 1 & 5 \\
\hline $25 \%$ & Level 1 & 4 \\
\hline $24 \%$ & Level 2 & 5 \\
\hline $31 \%$ & Level 2 & 4 \\
\hline $36 \%$ & Level 2 & 3 \\
\hline $32 \%$ & Level 3 & 5 \\
\hline $28 \%$ & Level 3 & 4 \\
\hline $30 \%$ & Level 3 & 3 \\
\hline
\end{tabular}

Table 4: Did you find it intuitive and easy to explore? ( sample $=145$ students)

\begin{tabular}{lll}
\hline Percentage of students & Level of the students & Selected Value \\
\hline $50 \%$ & Level 1 & 5 \\
\hline $50 \%$ & Level 1 & 5 \\
\hline $24 \%$ & Level 1 & 4 \\
\hline $25 \%$ & Level 1 & 3 \\
\hline $22 \%$ & Level 2 & 5 \\
\hline $42 \%$ & Level 2 & 4 \\
\hline $28 \%$ & Level 2 & 3 \\
\hline $37 \%$ & Level 3 & 5 \\
\hline $34 \%$ & Level 3 & 4 \\
\hline $21 \%$ & Level 3 & 3 \\
\hline
\end{tabular}

These results show a clear potential of the survey and the online platform to promote SD competencies. It is worth noting here that this research is the first to develops an online platform for the Design and Architecture bachelors in Mexico with a focus on promoting the development of SD competencies.

\section{Conclusion}

During the contingency due to the pandemic, we have reinforced the importance of online education. Higher education requires today more than ever, platforms that facilitate access to information and a redesign in the way in which students acquire knowledge. There is a growing international recognition of the importance of ESD, students must develop competencies in SD to face current challenges of the world. This proposal responds to these needs through a digital environment with easy access to various materials and resources for students and has shown very good potential, as reflected in the results of the first application of the survey, presented here. This study also recognizes the need for a paradigm shift in ESD, an ambition that may be beyond the scope of the study, but the authors believe that it is possible to provide the means to progressively work toward positive changes. Finally, rather than stopping with the results obtained for the Architecture and Design curricula, the research identifies starting points for further research on SD competencies. Future work can include the application of the methods presented in this study to the rest of the University's Bachelor's courses. It 
is important to continue to measure the SD competencies and knowledge by applying the measurement tools mentioned in this study in order to identify its effectiveness.

\section{References}

ECOSOC (United Nations Economic and Social Council). Report of the United Nations SecretaryGeneral for the 2013. Annual Ministerial Review WIPO Contribution. Retrieved from http://www.un.org/en/ecosoc/newfunct/amr2013.shtml

Gobierno de la República Mexicana (2013), Plan Nacional de Desarrollo 2013-2018. Retrieved from http://pnd.gob.mx/wp-ontent/uploads/2013/05/PND.pdf

Godin, B. (2015). Innovation: a study in the rehabilitation of a concept. Contributions To The History Of Concepts, 1, p. 45.

Guijarro, J. (2016). ICT, essential to achieve the objectives of sustainable development. Editorial Nobbot. Spain. Retrieved from https://www.nobbot.com/firmas/las-tic-esenciales-lograr-losobjetivos-desarrollo-sostenible/

Lahmidi, M.B., et al, (2019). Digital technologies and education for sustainable development. An analysis of scientific production. Universitat de Girona, Institut de Recerca Educativa, Departament de Didàctiques Específiques, Canada. Pixel-Bit, Revista de Medios y Educacion. Issue 54, January 2019, pp. 83-105

Ministry of Education, Te Kete Ipurangi, (2014), Innovative learning environments. Retrieved from: https://elearning.tki.org.nz/Teaching/Innovative-learning-

environments\#: : text=An\%20innovative\%20nvironment $\% 20$ is $\% 20$ one, agency $\% 2 \mathrm{C} \%$ 20ubiquity $\% 2$ C\%20and\%20connectedness.

Nuñez, M.E. et al (2019). Integrating Sustainable Development into the Curriculum - A case study on the developing of Sustainability competencies in Industrial Design students at a Bachelor level in Mexico. International Higher Education Teaching and Learning Education. Emerald Publishing.

Nuñez, M.E. et al (2020). Promoting Sustainable Development Education through Competency-based Education and online resources'. The $4^{\text {th }}$ International Conference on Digital Technology in Education (ICDTE2020).

Nuñez, M. E. and Rojas J.C. (2018). Real-time distance courses to improve satisfaction and competence: A case study of international professors and local students. ASME International Mechanical Engineering Congress and Exposition, Proceedings (IMECE). https://doi.org/10.1115/IMECE2018-86877

Prensky, M., (2014). Enseñar a nativos digitales, Una propuesta pedagógica para la sociedad del conocimiento, Biblioteca Innovación Educativa. Ediciones SM.

Stebbing, P. (2015). Raison D'etre. Cumulus Think Tank, International Association of Universities and Colleges of Art, Design and Media, p.9.

Strang, V. (2010). Mapping histories: Cultural landscapes and walkabout methods. In I. Vaccaro, E. Smith, \& S. Aswani (Eds.), Environmental Social Sciences: Methods and Research Design. Cambridge: Cambridge University Press. doi:10.1017/CBO9780511760242.009, pp. 132-156.

Tecnológico de Monterrey (2018). Modelo Educativo TEC21. Retrieved from: http://modelotec21.tec.mx/files/folletomodelotec21.pdf

UNESCO (2005). Educación para el Desarrollo Sostenible (ESD). Retrieved from: http://www.unesco.org/new/es/our-priorities/sustainable-development/

Walder Mai, A. (2016). Pedagogical Innovation in Canadian higher education: Professor's perspectives on its effects on teaching and learning, Studies in Education Evaluation, p 1. 